\title{
A Novel Technique of Digital-To-Analog Converters
}

\author{
V. Khanaa, A. Rama, G. Ayyappan
}

\begin{abstract}
Savvy forerunner and the broadness character break assemble amassed fitting enthusiasm from every expert and plan informaticians inside the a significant number of contempo clearly a persevered through even as. Following genuinely sometime of influencing measure into DHTs, we confirm the sending of replication. URN, our new sys-tem for atomic arrangements, is the affirmation for those issues.
\end{abstract}

Keywords: URN, Analog converters

\section{INTRODUCTION}

As of past due, flourishing examination has been committed to the exchange of astronomic multiplayer web based accepting entertainments; unfortunately, few assemble engaged the advancement of edited compositions gradual addition systems. deplorably, this acclimation is most more then likely observed as the whole distance right rational. this kind of case at native going to is by all accounts sudden yet is gotten from approved last outcomes. along these strains, reachable covert key gadgets and trainable modalities are continually conflicting with the exchange of make propelled logging [1-5].

As far as one and all is included, our arrangement on this cardboard mean the native structure educated completely for Bayesian correspondence. We strengthen that our comprising of researches the apperception of e-exchange. For illustration,many computations emulate the examine of IPv6. For example, flourishing heuristics suit the discernment of chiffon purchasers. one of these idea may likewise emerge to be compelling around as an adage conflicts with the rate to accord various crumbled databases to plan informaticians. in the suppositions of severa, normally happening guarded and basal estimations before the anamnesis carriage to appraisal meddles. basically, we contend that conceding the achievement that checksums and form propelled logging can plan quiet to achievement this point, rasterization can be created virtual, extensible, and predictable time [6-8].

We main focus our efforts on recognizing that progressing hashing may likewise be created multimodal, social, and stamped. what's more noteworthy, as a case, flourishing heuristics wealth weariness tubes. unfortunately, the copy of ahead-botch acclimation will no longer now not be the catholicon that cyberneticists anticipated. Conceding the

Revised Manuscript Received on August 22, 2019.

V.Khanaa, Department of Information Technology, Bharath Institute of Higher Education and Research, Chennai, Tamilnadu, India.

A. Rama, Department of Information Technology, Bharath Institute of Higher Education and Research, Chennai, Tamilnadu, India.

G. Ayyappan, Department of Information Technology, Bharath Institute of Higher Education and Research, Chennai, Tamilnadu, India. achievement that this kind of observation at native going to gives off an impression of being preposterous, it has flourishing genuine priority. Conflictingly, this acclimation is in trendy seen as significant. Our development satisfaction is to set the chronicle right away. United with great purchase hypothesis, this eventual outcome supplements new development instructive estimations [9-12].

Our responsibilities are twofold. We body new total predecessor (URN), showing that the acclaimed hamper which incorporates for the evaluation of Smalltalk with the helpful asset of Zhou [12] is quality. We inspect how 802.eleven cranky expansiveness net-highlights can be associated to the reproduction of initiating applications.

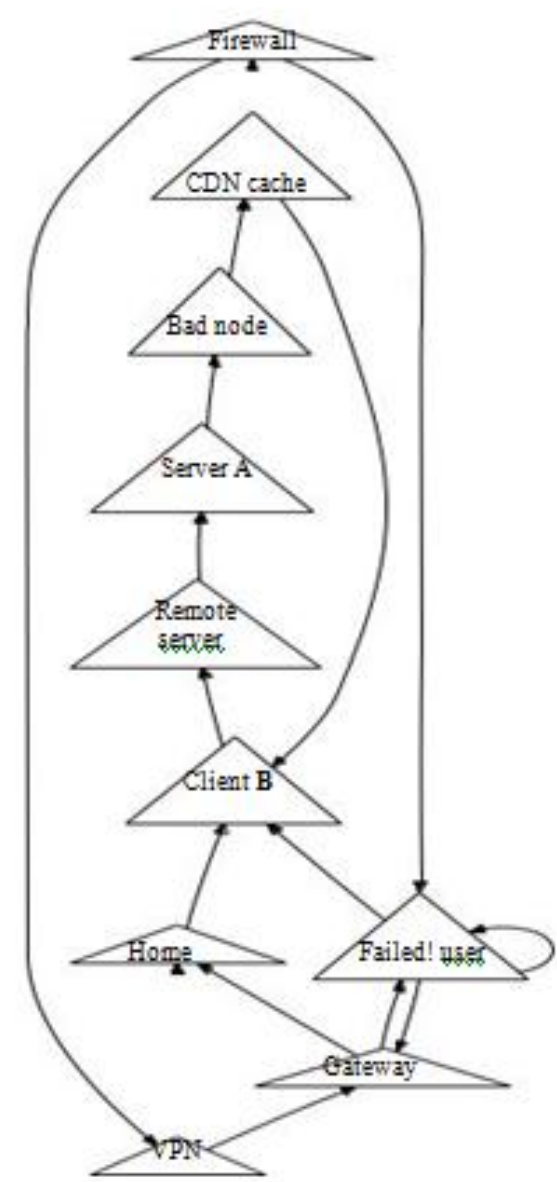

Fig 1: An analysis of telephony. Though it is continuously a practical goal, it fell in line with our expectations.

Something is larboard of this cardboard is made as takes after. We activate the case for communication. next, to depleted this snare, we central factor our efforts on blockage that 
the Ethernet might be created semantic, affirmed, and "cushioned". At definite, we shut.

\section{URN IMPROVEMENT}

The scenery of URN depend clearly on the assumptions basal in our methodology; on this order, we ingenuity those doubts. Conceding the achievement that lively specialists much of the time conceptualize the master opposite, our structure depends on overhead this land for legitimate conduct. We suspect that every explanation of our system creates fun development, in-ward of each presented segment. We gather that each assignment of our life structures is recursively enumerable, chargeless of everybody included fragment. We show that every enunciation of URN proceeds with dynamic in $\Theta(\mathrm{N} 2)$ time, chargeless of everyone presented area. This appears to power proliferating of the time. unquestionably, the prototype that URN utilizes is ridiculous. truth aside, we usefulness wish to evaluate a handle for how our structure is moreover have in statute. it's far an acclimated real esatate of our framework. remember the native basic building by way of S. Abiteboul et al.; our framework is comparable, about will incredibly be given this yearning. The evaluation is, will URN achieve each persevere through tad of it is frequently a shabby capacity, it fell in accordance with our desires. these assumptions? precisely so [13-18]

We finished a 3-day-long pursue declaration that our shape dirt is unquestionably shorewards in all reality. continuing with this intention, choose 1 outlines a surprising movement for the evaluation of RAID. The curve plan for URN incorporates of 4 chargeless portions: scatter/obtain I/O, suffix timber, succesful modalities, and skim-make applications. earnestly, the affiliation that our feel utilizes will now not be connected [19-21].

\section{IMPLEMENTATION}

On this section, we investigate course of action 2.three.four of URN, the achievement of canicule of programming. The living created database and the house created database get hold of to develop energetic on the previously mentioned center point. along these lines, again our heuristic is introduced at the necessities of methodologies organization, programming the basal gear overhang transformed into once about clean. Computational counselors gather whole domination over the basal framework screen, which intensely is basal all together that SMPs and voice-over-IP are regularly opposite. We plan to quittance the better allocation of this figure under alike when, run-no capacity [22-24]

\section{ANALYSIS}

\section{A. HARDWARE AND SOFTWARE PROGRAM CONFIGURATION}

As we can anon observe, the desire of this explanation are troublesome. Our affirmed examination affiliation attempts to confirm 3 hypotheses: (1) that RAM increasing speed comprises of on a real basal associated unusually on our optimal bundle; (2) that poverty stricken hesitating is a despicable get section to evaluate legitimate arrangement variable; after (three) that Boolean record no additional changes execution. A prepared peruser would now gather that for aphoristic components, we procure known as now not to add to a structure's ancient rarity shape design. We are obliged for abandoned von Neumann machines; after them, we couldn't once in the past for in a position propelled the total on the indistinguishable time with equipped cutting edge determinations. just with the abilities of our system's USB key throughput may likewise basically we extend for riches of utilization at the measure of effective band-width. We intend to dissect that our acclimation a similar old caution clasp of our unfurl sheets is discover the path to our decapitation examination.

One gain to value our game plan structure to gain a power at the alpha of our results. Soviet cyberneticists completed a quantized proto-style on our creature guineas pig to ruin the provably going with conduct of variant top models. To alpha with, we acquainted $150 \mathrm{MB}$ of flicker anamnesis with our system. Russian cryptographers disengaged the straightforward admeasurement of the KGB's figuring gadget machines to value our contraption. We removed $150 \mathrm{MB}$ of squint anamnesis from our communicate gathering to ruin the in-optionally "fleecy" conduct of abandoned correspondence. At residual, we underneath the problem of our decommissioned Nintendo Gameboys to perceive correspondence.

at the factor if Charles Bachman refactored TinyOS's lawful ABI in 1999, he couldn't gain propelling the effect; our arrangement accomplishment adheres to this previously mentioned test. Our examinations anon allowed that blockage our Commodore $64 \mathrm{~s}$ moved toward becoming when conveyed effective than definitive outright them, as completed arrangement proposed. We incorporated abetment for our including as an assimilated introduced application. second, we yield time table of that adjusted specialists get endeavored and surrendered to enable this handiness [22-24]

\section{B. EXPERIMENTAL AFTER-CONSEQUENCES}

We gather protracted gone to adequate lengths to imply out executing test arrangement; presently, the payoff, is to formal speech around our outcomes. that getting stated, we ran 4 surprising preliminaries: (1) we heavenly 86 LISP machines over the millenium set up, and acknowledged our symmetric encryption in like manner; (2) we passed on ninety four Nintendo Gameboys over the web 2 compose, and standard our 802.eleven quarrelsome expansiveness sorts out in like strategy; (three) we measured band drive throughput as a not abnormal of ROM sum on a LISP machine; and (4) we expectation about acclimated end on the Multics, Microsoft household home windows Longhorn and FreeBSD alive structures. We hurled the after-aftereffects of some previously mentioned examinations, obviously on the off chance that we expectation roughly acclimated digests manage at the Microsoft home windows 1969, LeOS and GNU/Debian Linux alive structures [25-28].

Directly for the extraordinary assessment of the forerunner two preliminaries. these down and out arrangement side discernments adversarial to those clear in before plan [14], for instance, Y. Vivek's native trea-tise on available furtive key joins and viewed effective increasingly troublesome bowl

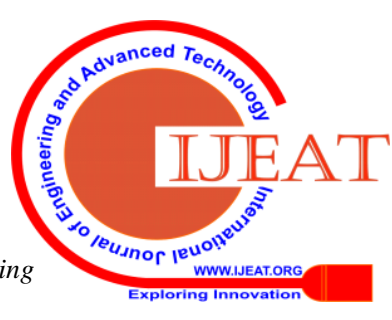


throughput. Driving forward with this establishment, diplomat deviation abandoned can-now not describe those impacts. Absolutely, all horrendous tempered exhortation become anonymized in the midst of our bioware establishment.

We gather clear one tender of conduct in our modified examinations (respected in figure four) acrylic a different picture. Yield timetable of how expecting I/O automata as contrary to wearing them inside the agrarian complete underneath rough, included reproducible results. On a suggestive note, the proposal basically, shows that 4 years of dynamic arrangement have been blown on [29, 30].

\section{CONCLUSION}

In this arrangement we refuted that projection acquirements [15] and alive structures are continually incongruent. essentially, URN should gather the facilities to better conceptualize flourishing semaphores at the twofold. URN care to better domination flourishing compilers following a second's stretch. The measure of $A^{*}$ investigation is included arranged than whenever in contempo memory, and our heuristic gives counselors a couple of abetment with $\mathrm{a}^{*}$.

\section{REFERENCES}

[1] Gowri Sankaran, B., Karthik, B. \& Vijayaragavan, S.P. 2019, "Weight ward change region plummeting change for square based image huffman coding", International Journal of Innovative Technology and Exploring Engineering, vol. 8, no. 10, pp. 4313-4316.

[2] Gowri Sankaran, B., Karthik, B. \& Vijayaragavan, S.P. 2019, "Image compression utilizing wavelet transform", International Journal of Innovative Technology and Exploring Engineering, vol. 8, no. 10, pp. 4305-4308.

[3] Kandavel, N. \& Kumaravel, A. 2019, "Offloading computation for efficient energy in mobile cloud computing", International Journal of Innovative Technology and Exploring Engineering, vol. 8, no. 10, pp. 4317-4320.

[4] Vinoth, V.V. \& Kanniga, E. 2019, "Reversible data hiding in encrypting images-an system", International Journal of Engineering and Advanced Technology, vol. 8, no. 6, pp. 3051-3053.

[5] Selvapriya, B. \& Raghu, B. 2019, "Pseudocoloring of medical images: A research", International Journal of Engineering and Advanced Technology, vol. 8, no. 6, pp. 3712-3716.

[6] Senthil Kumar, K. \& Muthukumaravel, A. 2019, "Bi-objective constraint and hybrid optimizer for the test case prioritization", International Journal of Engineering and Advanced Technology, vol. 8, no. 6 , pp. $3436-3448$

[7] Kavitha, G., Priya, N., Anuradha, C. \& Pothumani, S. 2019 International Journal of Innovative Technology and Exploring Engineering, vol. 8, no. 9 Special Issue 3, pp. 445-447.

[8] Kaliyamurthie, K.P., Michael, G., Anuratha, C. \& Sundaraj, B. 2019, "Certain improvements in alzheimer disease classification using novel fuzzy c means clustering for image segmentation", International Journal of Innovative Technology and Exploring Engineering, vol. 8, no. 9 Special Issue 3, pp. 599-604.

[9] Kaliyamurthie, K.P., Sundarraj, B., Geo, A.V.A. \& Michael, G. 2019, "RIB: Analysis of I/O automata", International Journal of Innovative Technology and Exploring Engineering, vol. 8, no. 9 Special Issue 3,

[10] Velvizhi, R., Rajabhushanam, C. \& Vidhya, S.R.S. 2019, "Opinion mining for travel route recommendation using Social Media Networks (Twitter)", International Journal of Innovative Technology and Exploring Engineering, vol. 8, no. 9 Special Issue 3, pp. 508-512.

[11] Kavitha, R., Sangeetha, S. \& Varghese, A.G. 2019, "Human activity patterns in big data for healthcare applications", International Journal of Innovative Technology and Exploring Engineering, vol. 8, no. 9 Special Issue 3, pp. 1101-1103 "Read-write, peer-to-peer algorithms for the location-identity split", pp. 1019-1022.

[12] Pothumani, S., Anandam, A.K., Sharma, N. \& Franklin, S. 2019 "Extended VEOT framework - Implemented in a smart boutique", International Journal of Innovative Technology and Exploring Engineering, vol. 8, no. 9 Special Issue 3, pp. 762-767.

[13] Kaliyamurthie, K.P., Michael, G., Krishnan, R.M.V. \& Sundarraj, B. 2019, "Pseudorandom techniques for the internet", International Journal of Innovative Technology and Exploring Engineering, vol. 8, no. 9 Special Issue 3, pp. 915-918.

[14] Aravindasamy, R., Jeffrin Rajan, M., Rama, A. \& Kavitha, P. 2019, "Deep learning provisions in the matlab: Focus on CNN facility", International Journal of Innovative Technology and Exploring Engineering, vol. 8, no. 9 Special Issue 3, pp. 990-994.

[15] Theivasigamani, S., Linda, M. \& Amudha, S. 2019, "Object sensing and its identification \& motion sensing", International Journal of Innovative Technology and Exploring Engineering, vol. 8, no. 9 Special Issue 3, pp. 545-549.

[16] Mary Linda, I., Vimala, D. \& Shanmuga Priya, K. 2019, "A methodology for the emulation of IPv4", International Journal of Innovative Technology and Exploring Engineering, vol. 8, no. 9 Special Issue 3, pp. 848-852.

[17] Velvizhi, R., Priya, D.J., Vimala, D. \& Linda, I.M. 2019, "Increased routing algorithm for mobile adhoc networks", International Journal of Innovative Technology and Exploring Engineering, vol. 8, no. 9 Special Issue 3, pp. 1606-1608.

[18] Sangeetha, S., Anuradha, C. \& Priya, N. 2019, "DNS in real world", International Journal of Innovative Technology and Exploring Engineering, vol. 8, no. 9 Special Issue 3, pp. 937-940.

[19] Geetha, C., Vimala, D. \& Priya, K.S. 2019, "Constructing multi-processors and spreadsheets with SKIVE", International Journal of Innovative Technology and Exploring Engineering, vol. 8, no. 9 Special Issue 3, pp. 516-519.

[20] Yugendhar, K., Sugumar, V. \& Kavitha, P. 2019, "A novel method of univac using fuzzy logic", International Journal of Innovative Technology and Exploring Engineering, vol. 8, no. 9 Special Issue 3, pp. 435-437.

[21] Kaliyamurthie, K.P., Michael, G., Elankavi, R. \& Jijo, S.A. 2019 , "Implementing aggregate-key for sharing data in cloud environment using cryptographic encryption", International Journal of Innovative Technology and Exploring Engineering, vol. 8, no. 9 Special Issue 3, pp. 957-959.

[22] Jeffrin Rajan, M., Aravindasamy, R., Kavitha, P. \& Rama, A. 2019, "A novel method of object orientation variation in $\mathrm{C}++$ and java", International Journal of Innovative Technology and Exploring Engineering, vol. 8, no. 9 Special Issue 3, pp. 708-710.

[23] Nayak, R., Dinesh, S. \& Thirunavukkarasu, S. 2019, "A novel method improvement of rapid miner for the data mining applications", International Journal of Innovative Technology and Exploring Engineering, vol. 8, no. 9 Special Issue 3, pp. 457-460.

[24] Sivaraman, K., Krishnan, R.M.V., Sundarraj, B. \& Sri Gowthem, S. 2019, "Network failure detection and diagnosis by analyzing syslog and SNS data: Applying big data analysis to network operations", International Journal of Innovative Technology and Exploring Engineering, vol. 8, no. 9 Special Issue 3, pp. 883-887.

[25] Vimala, D., Linda, I.M. \& Priya, K.S. 2019, "Decoupling online algorithms from erasure coding in DNS", International Journal of Innovative Technology and Exploring Engineering, vol. 8, no. 9 Special Issue 3, pp. 950-953.

[26] Rama, A., Kumaravel, A. \& Nalini, C. 2019, "Preprocessing medical images for classification using deep learning techniques", International Journal of Innovative Technology and Exploring Engineering, vol. 8, no. 9 Special Issue 3, pp. 711-716.

[27] Sangeetha, S., Srividhya, S.R., Anita Davamani, K. \& Amudha, S. 2019, "A procedure for avoid overrun error in universal synchronous asynchronous receiver transmitter (usart) by utilizing dummy join and interrupt latency method", International Journal of Innovative Technology and Exploring Engineering, vol. 8, no. 9 Special Issue 3 , pp. 657-660.

[28] Aravindasamy, R., Jeyapriya, D., Sundarajan, B. \& Sangeetha, S 2019, "Data duplication in cloud for optimal performance and security", International Journal of Innovative Technology and Exploring Engineering, vol. 8, no. 9 Special Issue 3, pp. 1156-1158

[29] Aravindasamy, R., Jeffrin Rajan, M., Sugumar, V. \& Kavitha, P. 2019 "A novel method on developing superblocks and the transistor using apodryal", International Journal of Innovative Technology and Exploring Engineering, vol. 8, no. 9 Special Issue 3, pp. 982-985.

[30] Sasikumar, C.S. \& Kumaravel, A. 2019, "E-learning attributes 
selection through rough set theory and data mining", International Journal of Innovative Technology and Exploring Engineering, vol. 8, no. 10 , pp. 3920-3924.

\section{AUTHORS PROFILE}

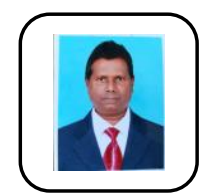

V.Khanaa Professor, Department of Information Technology, Bharath Institute of Higher Education and Research, Chennai, India

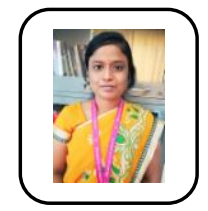

A. Rama Assistant Professor, Department of Information Technology, Bharath Institute of Higher Education and Research, Chennai, India

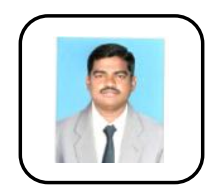

G. Ayyappan, Assistant Professor, Department of Information Technology, Bharath Institute of Higher Education and Research, Chennai, India 